\title{
Positive Psychology and Emotional Schedule: Building Healthy Self-Construction
}

\author{
Claus D. Stobäus ${ }^{1}$, Juan J. M. Mosquera ${ }^{2}$ \\ ${ }^{1}$ Postgraduate Programs in Education and in Biomedical Gerontology, Pontifical Chatolic University of Rio \\ Grande do Sul, Rio Grande do Sul, Brazil \\ ${ }^{2}$ Postgraduate Program in Education, Pontifical Chatolic University of Rio Grande do Sul, Rio Grande do Sul, \\ Brazil \\ Email: stobaus@pucrs.br
}

Received 4 December 2013; revised 5 January 2014; accepted 3 February 2014

Copyright (C) 2014 by authors and Scientific Research Publishing Inc.

This work is licensed under the Creative Commons Attribution International License (CC BY).

http://creativecommons.org/licenses/by/4.0/

(c) (i) Open Access

\begin{abstract}
This paper addresses the constituent elements of Positive Psychology, especially relating to healthy human development. It revises authors of Humanistic-Existential Psychology, the proposal to unite the human flourish to personal and social well-being, with the division into three major elements, namely: positive emotions, positive traits and positive institutions. It depends on building themselves a salutogenic health way as structure of a personological basis, constantly developing in the course of life, directing to reflections on the vital dynamics, throughout the existence, taking into account aspects of well-being and best development of expectations, feelings and values. And it provides interfaces Emotional Calendar recently stressed that allows us to understand how the environment and the person interact across the life cycle, reviewing the seasons, times and spaces, and significant events that act along the maturation and human maturity. All these elements lead to better understand and be able to act in a human development in all its phases and dimensionalities.
\end{abstract}

\section{Keywords}

Positive Psychology, Self-Construction, Emotional Calendar, Health, Lifespan

\section{Introduction}

At work, we resumed the prospected building itself during adulthood, deepening the development of identity, with the possibility of building itself, which is a process that lasts a lifetime and only regresses when there are no personalogical conditions and cultural rights for its development and recognition at the end of life. We 
highlighted in particular the writings of Freud and William James in the late nineteenth century, passing through the existential humanist as Jung, Rogers, Sartre, Maslow, reproduced more recently in Positive Psychology.

Although the theme of the person building itself has relied much on authors studying biographies, autobiographies and narratives and life stories, at the same time it is highlighted in the Psychology of Personality Development, taking into account their surroundings, developmental history and construction knowledge throughout his life. Positive Psychology, recalling aspects of personality development, especially in its more positive and healthy aspects, tends to include more than just the disease, understanding the human being as an intrinsically healthy person, being able to develop strengths and virtues that make your life better in quality and welfare. Along with these elements, affection and emotional life are included, especially in societies currently so technologized.

The Emotional Calendar theme is very recent and innovative in that it attempts to study influences of climates, environments and landscapes in human development, to realize their construction of themselves as well as the core values for this new millennium, as Sharp (2011). Again it is up to warn that the human being is not a neutral person, it has values, expectations and interests which affect your life. The intentional choice by the authors in this direction enables reflection about healthy, positive human development, helping to better build yourself.

\section{The Self-Construction}

Monereo \& Pozo (2011), in their work on the Identity in Psychology of Education, commented that human identity is a process that leads us to understand the uniqueness and diversity that persons develop throughout their lives and aims to understanding that are unique, while plural. Warn about the formation of the human person and group belonging, increasing awareness of yourself, or even as an extension of our brains, well described Damásio (2011), when using the metaphor that the brain creates the man. Identity, then, is a process, not a product, its construction lasts a lifetime and is responsible for the recognition of our own person and construction we set ourselves, influenced by the other, living into a society.

Ramírez (cited in Monereo \& Pozo, 2011) reports that elements such as culture, society, ethnicity or language are aspects that shape the human in all its construction of personality, lifelong, and that the study of social and cultural aspects should be understood as a framework ample involving himself, includes his experiences as a human being, contextualized in constituent elements as the body we have, our inter-subjectivities, desires, motives, capabilities. Identity and self are studied by integrating aspects of Education and Psychology, but also appear in the literature, as in Fernando Pessoa (2006), the work's deeper self and other selves, on human life and our ability to encompass the human diversity. The poetry, narrative literature and demonstrate that understanding the building itself is not only a scientific nature, but it may refer to the Arts and Letters.

This constant construction of myself, as I recognize myself as an individual, also open prospects for the variety of other deep selves, the human meaning, the possibility of being plural and allow me new insights that extend myself in terms of dimensions as a human being, capable of exchanging values, strengths and virtues, knowledge and ideas, skills and attitudes.

Delory-Momberger (2008: p. 63), where refers to biographical construction and the itself project, highlights that the biographical construction is part of temporal dynamics that closely articulates three dimensions: past, present and future, and these three-dimensional design in the future, forward. Just understand that the most sense for our existence is to construct projects that take us to new horizons and new possibilities. Points out (p. 65) that "biographical construction is therefore the attempt necessarily unfinished and repeated indefinitely, to reduce the distance that separates the self from its primary project”. We are continually developing a vital balance that gives us an overview of what we are, and who we can become.

The construction that each makes of himself is not neutral but is a continuum of values and meanings that lead us to integrate the entire perspective of this process of identity through the different possibilities that encourage us to think that we are dynamic beings, not stuck in time, but constantly (re)building our speech, our experiences, our way of understanding the world, from possibilities, interests and valuations.

Berger (2008: p. XI) says that "every year, every day and even every hour is a gift to be filled with happiness and work. For this is what I believe". For the author, adulthood is the development of stages: initial adulthood, middle adulthood and aging. This step is also called as late adulthood, as emphasized Ferreira, Goulart, Stobäus and Mosquera (2012). We also point out that the entire life cycle, from conception to death, is a continuum of changes in vital ways that give meaning to our existence, through what is called Sharp (2011) as Emotional Calendar. 
It is not our intention to deepen the formulation of different times of adult life, but understanding the living space the elements that we consider most important.

As reported Mosquera (1987), we must understand that the young adult is in extremely challenging, because he/her is early in the deepest project to consolidate their identity and start building yourself as an adult person.

Due to neuroscientific advances and the development of personality, we can say that the socio-economic situation influences the construction of an adult personality that allows for the recovery of him/herself and especially more clearly anticipates the horizon of new possibilities ahead. It is the stage of building and enhancing social relationships, starting in the profession/job, leaving home, take more responsibility.

In middle adulthood, primarily denominated stage of achievement of maturity, have a responsibility to prepare the future of the younger ones, and to maintain the capacity of well-being of present and future late adults, says Mosquera (1987).

Late adulthood has worried many authors and increasingly presents possibilities of living for people who find themselves in this existential stage, especially when we have the possibility of longevity with quality of life than 110 - 120 years, as highlighted Fernández-Balleteros (2009).

In this step, a topic that has called us much attention is the development of wisdom, with the current possibility of maintaining brain function. Wisdom has been studied by classical authors such as Erik Erikson, contemporaneously by the portuguese author Helena Marchand (2005a), which devotes a chapter of his book to his study, noting that "wisdom is a particularly complex concept", and devotes the entire book (Marchand, 2005b) to the subject. Says that the concept of wisdom is broad, encompassing cognitive dimensions that supports a specific form of knowledge, cognitive style guy named reflexivity and conative dimension, which means decentration and empathy. It is also the possibility to extend our knowledge and possibilities of intelligent emotional approach with all those around us and which did and do (and will) part of our life.

Finally, we draw attention to this whole building itself is eminently personalogic and sociocultural character. The walk, for example in the field of Education, is made through the meeting of the identity of the teacher with the identity of the learner, as pointed out Falsafi and Coll (cited Monereo \& Pozo, 2011), that the identity is precisely the result of the encounter of what the authors state that it is a notion of Baktin, called dialogism, in which people give meaning to their existence by defining its specific place in it, in an operation that perform in time and cognitive space, with the basic categories of perception. Mentioning that the construction of identity and what we call the construction of the self is the kind of materialization of dialogism, a way of giving meaning to our participation in our specific contexts.

So we can say that the analysis of identity can be understood as the analysis of the process by which people come to make sense of their participation in learning activities through the recognition of themselves as learners and that the values and emotions accompany this recognition, adding that, to see ourselves as we really are, we also need to take ownership in the comments of the other, so are the other categorizations that allow us better objectify our own perception.

In other words, I am also the author of myself. Thus, in reaching a crucial point in our reflection, we can understand that the building itself is a process at the same cognitive, affective and socio-cultural time. Caters to what we have studied over all these years, the identity as a process mater, self-image and self-esteem and the eigenvalues of our own existence, and all this combined is now what we call the Self. A very important point is the consideration and appreciation that we developed for our own person, which is the basis of the whole structure of what we call positive emotions and feelings.

Just like there is no end to old to learn or experience emotion, there is also no age to the end of the spiritual development of human beings, since the construction of spirituality accompanies the building itself and the recognition of their integrity as a person projected in future.

We reiterate, once again, that this whole theme can be recognized both in the most advanced and progressive Psychology we call as Positive Psychology, as an Education able to establish new forms of mental organization, greater capacity for affection and completeness in the world in surrounds.

\section{Contributions of Positive Psychology}

Positive Psychology is extremely significant to be able to understand and study a more advanced line for debate and analysis in academic circles in recent times.

Poseck (2008) draws attention to the movement we know as Positive Psychology appeared in the United 
States in the late 90s of last century. Complements to a consensus to establish its formal beginning in the inaugural conference that gave Seligman, as began his stage as president of the American Psychological Association (APA) in 1998. He pointed out that there was excessive interest in Psychology to describe the disease and more negative aspects of personality, forgetting the positives, especially emotions, feelings, values and strengths of the human being. Emphasized that one of the initiators of Positive Psychology was Maslow (1991), who wrote a chapter in one of his books on the Psychology of positive point of view.

Maslow is recognized as an author who was highly relevant to the study of so-called Humanistic Psychology, undoubtedly legitimate predecessor of Positive Psychology.

It is important to remember that Psychology as a Human Science eminently originally had three purposes: curing mental illness, making the lives of people happier and identify and cultivate talent. This was unfortunately postponed and Psychology acquired a most healing nature of that Health promotion.

Seligman, according Poseck (2008), forwarded to the APA committee that now was the time to resume the original goals of Psychology and that he should not be a simple Public Health branch or extension of Medicine.

From its earliest manifestations, Seligman drew support from both private institutions and public institutions and thus came to confirm and usher in a network of Positive Psychology, which appeared in the journal American Psychologist published in the beginning of the XXI century. We would also like to draw the attention on Positive Psychology as having close ties with the Health Psychology and both are extremely important for understanding what may lead to the construction of Self and the development of healthier forms of human personality.

It is obvious that we need a more healthy view of human life, which is, in our view, widely valued by Positive Psychology when broadens the focus of interest in humans to encompass the ideas of character strengths and virtues without put aside emotions and feelings. The main concern is not to overlook the negative aspects, our focus is to seek to emphasize the healthiest points, when you look beyond the disease and seek treatment and healthier transformations, to promote and understand what we have already called attention human strongholds.

The pillars of Positive Psychology are based on three major elements as follows: Positive Emotions, Positive Traits and Positive Institutions.

Positive Emotions, which can be the joy, hope, devotion and gratitude, seeming to have been forgotten for many years.

We recall that Mosquera (1978) was concerned with the feelings of teachers in different educational levels, already in his doctoral Thesis, seeing the affection and emotional development as very important in the lives of teachers. On the other hand, studies by different researchers have drawn attention since the late twentieth century to the early twenty-first century, on the importance of the affective life in human beings and, especially, the role of affect in the teaching and learning. Therefore, the positive emotions still try to look better are, by nature, one of the strongest pillars of Positive Psychology.

Positive Traits, another important step towards achieving a fulfilling life or as recognized Seligman, a bigger and better well-being, must have knowledge and cultivate those inner variables or personality traits that help us be better and happier pillar. Recall that in the twentieth century, in its beginnings, the psychologist Allport (1973) already gave the following explanation of the human personality: would the dynamic organization in the person of those unique and original psychophysical systems that determine adjustments to their environment.

We have here one of the main points of the timing and emotional at the same time, the idea that these systems are clear ways to search for character strengths and virtues, used by psychologists, psychiatrists, educators, caregivers and teachers to get to help people and promote more and better welfare. All this is observed in a very specific way in achieving Positive Psychology, his statement in the XXI century.

The third pillar is Positive Institutions, as in societies that aspire to own a set that supports, encourages and enhances positive emotions, positive feelings and personal strengths should thrive on Positive Institutions, as are democracies, well-structured family, the freedom of information and communication, economic and social security and especially, good Education. All this are, in addition to its vital to academic work and social importance, great promoters of the development of identity and, very strongly, the building itself, especially in enablers and provocative environment. We are convinced that, as educators and caregivers, we must be extremely linked to human well-being, especially when picked in healthy institutional levels of motivation, growth and self-realization.

It would be worthwhile to mention that Positive Psychology has and should have a die cutting and scientific with rigor and empirical soundness. We try to say here that Positive Psychology is absolutely not a utopian form 
of work, much less proposals for self-help, but a concrete way to call on our understanding about health and wellness.

As scholars and teachers firmly integrated in the Humanistic-Existential Psychology would also like to say that we are fully aware of how much that helped in understanding the psychology building itself, from authors such as Rogers, Maslow and Fromm, which highlighted that these principles also believe. As we already said, Maslow (1991) found itself antecedents of Positive Psychology, in his book Motivation and Personality, and especially the concept of self-actualization.

Positive Psychology has been of interest to another portuguese author, Barros de Oliveira (2010), being one of the first authors who worked this issue in Portugal. For him, and we agree with these ideas that particularly Psychology has studied the negative personality functioning, especially negative emotions (depression, discouragement, anxiety, loneliness, aggression, guilt, shyness). Therefore, he says, needs more concrete and meaningful view of Health, therefore more salutogenic, trying new approaches. It also shows us that in the middle of the first decade of this century, Positive Psychology was in full swing especially concerned with the forces of character and virtues that people should develop, in a world in flux.

Considers it very important to know aspects like love, happiness, joy, sense of humor, optimism, hope, forgiveness, courage, beauty, the meaning of life, spirituality and finally the higher topic, titled wisdom. Still puts in other subjects that could supplement these positive aspects of life, including: altruism, friendship, authenticity, compassion, patience, creativity, efficiency, empathy, excellence, flexibility, fluency, gratitude, honesty, humility, patience, serenity and resilience.

As we can see, these virtues and these forts are of extraordinary importance for understanding the construction of self and identity development, and it is possible that we realized that all this can be carried out through an Education that is closely linked to the construction him/herself, as it was placed at the beginning of this work. We believe that today's developed on Positive Psychology studies allow us a new way of seeing reality and understand how we are building our personality through different aspects that make up the world of education, of developing societies and culture.

We would also like to state that Positive Psychology is a task of international dimensions and comes to Latin America, in works like Solano (2010), which draws attention to cross-cultural research studies and practices applied to the well-being of society, teacher welfare and well-being of caregivers. Therefore we should ask: What makes people happier? What is a good life? How to improve from our strengths and not our faults? And finally, what turns us into virtuous people?

Several researches in this new focus of Positive Psychology show themes like welfare that will be emphasized in the book Blossom Seligman (2011), beside those virtues and strengths that were identified by the Portuguese author Barros de Oliveira to.

Solano (2010) points out that, in the twentieth century, Psychology was engaged primarily in studying the human needs and its possible repair, such as depression, psychopathological disorders, stress, anxiety, additions to drugs, suicide and eating disorders. Therefore, the Hispanic author believes that a Psychology of the XXI century should not only occupy in repairing the psychological damage, but how leverage on the positive qualities of all human beings and deserve to develop them. We should not ignore the pain and sickness, but, as caregivers, educators and historians of human life, we must enhance the health and enhance flowering.

Referring to the book of Seligman (2011: p. 23), Blossom calls for a new Positive Psychology to consider the application that must occur in different areas of knowledge and human life, and attracted much attention in the book's preface, "this book will help you flourish". Adds that his ideas have changed since the publication of the book Authentic Happiness, and that psychology itself is also changing.

This new Psychology emphasizes the welfare and concern is to make the implementation of Authentic Happiness Theory to the Theory of Welfare. The fundamental issue for him was happiness before, now is the welfare, with five major dimensions: positive emotion, engagement, meaning, positive relationships and achievement. Also draws our attention to the great goal is to increase flowering, we understand the construction of the Self, beyond the engagement of oneself on oneself, the engagement of a person in herself and in others. Added the search for meaning, which already is in other authors such as Maslow and Frankl, and evolution of the positive relationships we have with other human beings, to achieve an evolution in human life itself.

Seligman (2011) points out that welfare is a construct and that is the welfare and not happiness is the topic of Positive Psychology, and again he calls our attention to the welfare reprises the five elements he considers fundamental, repeating that are positive emotions (happiness and satisfaction with life are aspects of it), engagement, 
that is, in our opinion, a great virtue, which is the ability to be constantly inserted in the experience itself and the construction of self and others, and finally just to name the relationship, establish links increasingly affectionate relationships between human beings and their institutions, all this leads them to have meaning and fulfillment.

Positive Psychology is understood as the study of optimal psychological functioning, from the point of view of individuals, groups and institutions. As we have seen, he innovates adding that humans have the ability to (Self) to address and propose their own future, with self-flourish.

\section{A Challenging New Idea: The Emotional Calendar}

We were able to get in touch with the work of Sharp (2011), entitled The Emotional Calendar, in which he notes that attempts to understand the influences of the seasons and the emotional stages during life to be happier, feel fulfilled and control his personal life. The work draws our attention because it unites a whole view of Psychiatry with Psychology, the environment and their own life stories, and this is extremely important to better understand what happens to us as we go through life evolution: the minutes, the hours, days, months and years.

Citing Sharp (2011: p. 19), we are accustomed to understand our life as a thread of continuity, so he says that:

To understand your emotional calendar, you have to start thinking about life differently to how you were doing until now not like it was the steady sound of a drum of days, weeks, months and years, but as it were a succession of time periods of different duration and each with different influences.

Adds that:

[...] Our emotional calendar is less structured than our daily schedule and effect and sometimes subtle and other more notorious, but the much less predictable sometimes it is difficult to handle and provokes conflicts but always comes full of emotions and meanings.

We would like to draw attention to these ideas in place before a new reality, the emotional life is of great importance to understand how we develop in different seasons and how each event or significant event is to be able to understand life in all its diversity and meaning. In the first part of his book, puts the elements about the climate in most of the United States, the four seasons of the year, he said, would be summer "super charged", the reality of autumn, the large hand of winter, and spring and that it to mean.

Through these stations he wants to establish the feelings that develop in each of them, especially the events that were scored to determine the narratives of life that people have with the nature of his sentimental and emotional life.

Here we should remember that we can make a reference to human life itself, in which the spring mean childhood and adolescence, summer is young adulthood, autumn is the average adult life and winter is late adulthood. These stations are closely linked to the course of the life cycle and the building itself.

As we know, spring is a stage of flowering in which everything springs and germinates, when life presents its most environmental listed flourish aspect, because we know full well that childhood and adolescence are very significant moments in construction and they help enable preparing for the biggest stage of life, that is adulthood. We must remember that this topic has already been noted at the time that we were aware about life as part of preparing and training for the other existential moments.

We believe that the Emotional Calendar not measured in chronological years or in certain years, but it has to do with what marks our existence as a human being. Moreover, the metaphor of the bloom has a very important meaning for representing the dawn of spring, i.e., childhood and adolescence.

Our understanding of the work of Seligman (2011) is that the bloom is a demand for welfare and reunion with our own person, in childhood and adolescence, and that this demand occurs in different life scenarios and circumstantial different times.

The stage of young adulthood is closely linked to summer, the strength and energy of light and shadows, and at the same time, the establishment of a new framework for addressing adult vital moments. Clearly these moments we realize how much summer is symbolically light and heat, power and energy, determination of our destinies and prospects facing the future and for the achievement of our life listed proposals for the next steps, the structuring and development.

In consideration of the autumn of life emphasize the size of the average adult life, which is golden and transition time gathering up the fruits of what was sown earlier, which presents itself as probably the most important 
phase of life. This step is fraught with great meanings, we can realize how much we are responsible for our construction and the construction of others. It is evident that the average adult life in all human beings, regardless of their origin and their status, correlates with deep meanings, which lead us to the "transmutation of nature in the transmutation of our nature".

We recall here the extraordinary piece of music by Antonio Vivaldi, in which the fall appears to own luminosity of an opulent decline of sounds and forms that lead us to meditation as this stage of life people need to think about your "inner music", which is full of feelings, values and attitudes.

And finally the winter, which may be associated with late adulthood also called aging, and that would relate to the spring of life. We know that more and more we are able to live longer, and that this is the urgent need to provide more opportunities and incentives to those persons who have attained reach what is called the moment of attention between life and death.

By making these reflections, we recall here that are reflections emanating from the excellent book by Sharp (2011) on the Emotional Calendar. So add that angers, fears, depression, or happiness, well-being and joy has a lot to do with the ambience in which we find ourselves and that this can all be narrated taking into account that every human being is a unique history and unrepeatable, which can be told to himself and others, and that when we make our history, we make the narrative of our feelings, values and expectations.

Sharp (2011) made use of most of the stories of his patients, or persons authorized to count in its history, to understand the different moments that passed the seasons of life and in which they developed their depression or their flourishing. All this is extremely important in order to understand the miracle of human health or disease and understand that side of our "inner landscape", we also have the "landscape that surrounds us" and that often these landscapes are the edge of the path of our life wither dimensionality.

The second part of the book Sharp (2011) contemplates the environmental factors that are heat and cold, light and darkness, wind and storm, weather disasters. As we can see, the author provides a rich analysis of what happens in the environment and how it influences human subjectivity and how these factors may be closely linked to emotional factors and how, from them, we have inter-influences that bring memories with psychic environmental.

The third part of the book is that probably most concerns us, as explains how we differentiate ourselves and, at the same time, support points between each of us and others. So, remembering what the author says (p. 179), "the personal emotional calendar is unique, constructed by genetic disposition and individual experiences and influenced heavily by an extraordinary collection of both accidental episodes as predictable”.

This idea is fundamental, as Sharp (2011) shows us how it is possible to entangle the entire human living while ambience that surrounds us and what we denominated inner landscape. We would like to add another idea struck us in reading the book, that the timetable people tend to coincide to some extent, based on shared similar views and experiences. And he adds (p. 179):

On the other hand surprises me again and again the many cases of close friends, parents and children, including husbands and wives whose lives and experiences coincide, but the answers are completely different, whether physical or emotional already. This may tell us as we consider how important the building itself, in certain environments, in certain countries and in certain situations.

Sharp (2011) still insists that we can not predict that episode of life can become a key point on emotional, as our brain has a complex strategy to register and retrieve memories. Therefore, although every thing we look at, hear, touch and taste is a keepsake that can become very significant.

All these ideas presented are of utmost importance for the understanding of Emotional Calendar, so it is not surprising that our calendar is irrevocably linked with our past, while large events can have very specific meanings in certain of the stations.

Therefore inferred that there are "official calendars" and that there are key moments in each year or in the years of our life, "meaningful holidays" that can excite or depress us can, taking into account our personal memories and our socio-cultural memories, along our lives.

Sharp's (2011) book is an extraordinary addition to what we understand about the history of the people, within the history of time and in different environments and climates. The Emotional Calendar is a way to reflect on what he calls our emotional memory, our personal calendar, our social calendar, and this influences our estimates on the inside, that is, our subjectivity, as well as on the outside, our ambience.

We are cultural beings and subjective at the same time are environmental things, and unite this means better 
develop our own building itself, passing through key moments of our lives and the meanings we give to it.

\section{Final Comments}

After foregoing ideas about aspects of the building of ourselves, with the contributions of Positive Psychology and the elements of Emotional Calendar, we realize that all these have integration and interaction, which underscore the necessity of living and power (re)counting our own history.

The human being is a being who learns to narrate to himself and about himself, which has almost an obligation to flourish, passing through stages of emotional calendar. Increasingly we realize that if rationality is important, it is also a very important and significant history of affectivity and the story of our experiences in the world that touched our lives.

To conclude this study, we do so with the conviction that it is important to emphasize that human life itself is a mystery that can flourish in what we call the sensitivity of our feeling for the light and the shadows, with the assurance that every human being is a story that is never finished, and it is unique and unrepeatable.

\section{References}

Allport, G. (1973). Personalidade. São Paulo: EPU/EDUSP.

Barros de Oliveira, J. H. (2010). Psicologia Positiva. Uma nova psicologia. Porto: Legis Editora.

Berger, K. S. (2008). Psicología del desarrollo. Adultez y Vejez. Madrid: Editorial Médica Panamericana.

Damásio, A. (2011). E o cérebro criou o homem. São Paulo: Companhia das Letras.

Delory-Momberger, C. (2008). Biografia e educação: figuras do indivíduo-projeto. Natal: EDUFRN; São Paulo: Paulus.

Fernández-Balleteros, R. (2009). Envejecimiento activo. Contribuciones de la Psicología. Madrid: Pirámide.

Ferreira, A. J., Goulart, D., Stobäus, C. D., \& Mosquera, J. J. M. (2012). Investindo na Educação para um envelhecimento com qualidade de vida. In A. J. Ferreira, C. D. Stobäus, D. Goulart, \& J. J. M. Mosquera (Eds.), Educação e Envelhecimento. Porto Alegre: EDIPUCRS. (on-line) http://www.pucrs.br/edipucrs

Marchand, H. (2005a). Psicologia do adulto e do idoso. Coimbra: Quarteto.

Marchand, H. (2005b). A idade da sabedoria. Porto: Âmbar.

Maslow, A. (1991). Motivación y personalidad. Madrid: Díaz de Santos.

Monereo, C., \& Pozo, J. I. (2011). La identidad en Psicología de la Educación. Necesidad, utilidad y límites. Madrid: Narcea.

Mosquera, J. J. M. (1978). O professor como pessoa. Porto Alegre: Sulina.

Mosquera, J. J. M. (1987). Vida Adulta (3 ed.). Porto Alegre: Sulina.

Pessoa, F. (2006). O eu profundo e os outros eus. Rio de Janeiro: Nova Fronteira.

Poseck, B. V. (2008). Psicología positiva. Una nueva forma de entender la Psicología. Madrid: Calamar Ediciones.

Seligman, M. E. P. (2011). Florescer: Uma nova compreensão sobre a natureza da felicidade e do bem-estar. Rio de Janeiro: Objetiva.

Sharp, J. R. (2011). El calendario emocional. Barcelona: Luciérnaga Nova.

Solano, A. C. (2010). Fundamentos de Psicología Positiva. Buenos Aires: Paidós. 